\title{
CORPOS IMPERFEITOS: AS TESES MÉDICAS SOBRE INFERTILIDADE FEMININA APRESENTADAS À FACULDADE DE MEDICINA DO RIO DE JANEIRO NAS PRIMEIRAS DÉCADAS DO SÉCULO XX
}

\author{
IMPERFECT BODIES: THE MEDICAL THESIS ABOUT \\ INFERTILITY FEMININE PRESENTED TO THE FACULTY OF \\ MEDICINE OF RIO DE JANEIRO IN THE FIRST DECADES OF THE \\ TWENTIETH CENTURY
}

\author{
Georgiane Garabely Heil Vázquez ${ }^{1}$
}

RESUMO: Este artigo buscou problematizar o saber médico acerca da infertilidade feminina nas primeiras décadas do século XX. Para isso, foram analisadas teses apresentadas à Faculdade de Medicina do Rio de Janeiro (FMRJ) e defendidas nas cadeiras de Higiene e Ginecologia/ Obstetrícia. Em linhas gerais foi observado que além de investigações e tratamentos clínicos, a infertilidade feminina foi debatida por médicos do período como uma questão moral, que envolvia desejo e recusa feminina à maternidade.

PALAVRAS-CHAVE: infertilidade; medicina; mulheres; maternidade.

ABSTRACT: This article sought to problematize medical knowledge about female infertility in the first decades of the 20th century. For this, we analyzed theses presented to the Faculty of Medicine of Rio de Janeiro (FMRJ) and defended in the Hygiene and Gynecology / Obstetrics chairs. In general lines, it was observed that besides investigations and clinical treatments, female infertility was debated by doctors of the period as a moral issue which involved female desire and refusal to motherhood.

KEYWORDS: infertility, medicine, women, motherhood.

\footnotetext{
*Pesquisa derivada de tese de doutorado defendida na Universidade Federal do Paraná com financiamento CAPES.

${ }^{1}$ Professora do Departamento de História e do Programa de Pós-Graduação em História da Universidade Estadual de Ponta Grossa ( UEPG) email: profgeorgiane@ hotmail.com
} 
Introdução

A mulher mãe é a mulher completa; a mulher jovem, bella, rica, invejada de todas as mulheres e desejada de todos os homens, rainha do mundo e dos corações, não é, e não póde ser feliz, se nella não palpitar a maternidade.

(Mantegazza, 1924)

Elizabeth Badinter $(1985 ; 2011)$ já apontou para a construção de um ideal de maternidade moldado historicamente desde meados do século XVIII e que foi sendo crescentemente disseminado por diversas saberes e discursos, dentre esses, o conhecimento médico.

Ser mãe e, obrigatoriamente, ser boa mãe, foram funções atribuídas às mulheres por diferentes instituições. Assim, a medicina em concordância com outras áreas do social, vai se questionar sobre corpos femininos impossibilitados de engravidar. Porém, mais temível ainda, no início do século $\mathrm{XX}$, médicos se questionavam sobre mulheres que, mesmo tendo condições biológicas para engravidar, optavam por evitar filhos.

Infertilidade ou a esterilidade ${ }^{2}$ passaram cada vez mais para um campo do saber médico e privado. As frustações sobre o desejo de uma gravidez que não se efetiva, ou a dificuldade em manter uma gestação, são martírios narrados para o médico confidente, o escolhido para acompanhar e curar a impossibilidade do filho. No corpo do século XX, Moulin (2008) argumenta que não há mais espaço para o exibicionismo de nenhum tipo de doença. A doença, a limitação, a "imperfeição", são demarcadas e classificadas pela ótica médica, e o corpo é o lugar onde a pessoa deve revelar sua saúde, seu bemestar, sua felicidade. Sendo assim, a doença, a incapacidade total ou parcial, o defeito, passaram a ser integrados à rubrica da infelicidade, do confidencial, do privado.

No que tange especificamente à ausência da gestação, pode-se mencionar que no século XX se intensificou a ideia de que as mulheres nãomães estavam doentes e necessitavam de intervenções médicas sobre seus corpos. A experiência social da ausência de maternidade se tornou uma

\footnotetext{
${ }^{2}$ A infertilidade é entendida como a dificuldade para a concepção. Já a esterilidade é a total impossibilidade de concepção, mesmo com estímulo médico.
} 
experiência médico/clínica entre paciente e médico, sendo que a palavra final muitas vezes era dada pelo médico.

Para entender o debate sobre os corpos, em especial os corpos femininos inférteis, me amparo nos estudos culturais e feministas. Dessa forma, os apontamentos de Michel Foucault (1999) são importantes justamente porque permitem compreender o corpo como uma construção linguística e sociocultural, produto de uma espécie de saber/poder permeado por relações sociais. Assim, os múltiplos processos pelos quais os corpos femininos passaram a ser relacionados com a gestação e a maternidade são produtos dessa relação de saber/poder. Conceber, gestar, parir, amar, maternar, abortar ou mesmo lutar contra o corpo para alcançar tais intentos são percebidos aqui como práticas culturais, abarcadas por formas de regulação moral e social e mergulhadas em relações históricas que possibilitam compreender que as subjetividades não se encontram fora dos processos sociais e sobretudo da ordem discursiva que as produzem.

Ao propor a análise do discurso médico sobre o corpo feminino inférteis ou sobre mulheres que não desejavam engravidar, acabei por me deparar com a emergência de uma lógica de educação sobre tais corpos. Isso se deu pelo fato de que a modernidade e seu projeto civilizador elegeu os corpos como meio de sociabilidade e fonte de produção das riquezas do Estado-Nação (FOUCAULT, 1999), assim a produção de indivíduos saudáveis era vista como fundamental para a prosperidade geral. A saúde da população passou a se tornar política de Estado, e os corpos dos sujeitos e cidadãos, em especial os corpos femininos em sua função reprodutiva, ganharam uma dimensão amplificada pela lógica normativa do discurso médico.

O médico passou a ocupar lugar de poder na relação dos indivíduos com seus corpos. Mulheres que possuíam alterações no "padrão" de organismo adequado para suas "funções naturais", como a reprodução, despertaram interesse dos médicos. Além disso, os médicos também se inquietavam com mulheres que deliberadamente evitavam engravidar e, portanto, rejeitavam a maternidade. Assim, acredito que a análise de parte do saber médico produzido 
sobre as mulheres é fundamental para compreender como a ausência de filhos foi tratada socialmente no Brasil nas primeiras décadas do século XX.

Desta forma, este artigo propõe a análise de teses médicas vinculadas às dificuldades para engravidar, à esterilidade, e mesmo teses que se pretendiam na condição de analisar corpos e mulheres que optavam por evitar a gestação nas primeiras décadas do século XX. Tal documentação está sobre a guarda da Casa de Oswaldo Cruz (COC/Fiocruz) e se encontra no setor de obras raras da biblioteca de Manguinhos.

Como objetivo central deste debate, pretendo contribuir para elaboração de parte da história da medicina no Brasil, em especial, da medicina voltada para as mulheres, com a atual abordagem analítica dos estudos de gênero, ou seja, articular sobre o viés historiográfico os campos da medicina e da cultura. Tais analises são pertinentes na medida em que ampliam debates socioculturais sobre a maternidade e o conhecimento médico sobre os corpos femininos.

Investigações sobre corpos femininos: as teses médicas

Maria Izilda Matos aponta que, distantes da imagem aterrorizante de cirurgiões cheios de dúvidas, os médicos, entre fins do século XIX e início do século XX, paulatinamente adquirem respeitabilidade diante de sua clientela. Essa valorização do saber médico sobre as mulheres foi reforçada por meio do "cientificismo-higienista" que permitiu "[...] aos médicos expandir o controle sobre a família, normatizando os corpos e os procedimentos, disciplinando a sociedade, ordenando o sexo e os prazeres" (MATOS, 2000: 92). Em concordância a isso, Ana Paula Vosne Martins (2000), argumenta que o interesse em conhecer e escrever sobre as especificidades do corpo feminino ganhou fôlego a partir da segunda metade dos oitocentos. Isso é verificado pelo fato de que a prática referente ao diagnóstico e ao tratamento de enfermidades do corpo feminino recebeu o estatuto de especialidade dentro da medicina. A nova especialidade médica foi definida como a "ciência da mulher". 
(MARTINS, 2000: 113-116). Foi, portanto, nas últimas décadas do século XIX, que a mulher passou a ser reconhecida como uma categoria específica entre a clientela dos médicos, definindo-se, a partir de então, como um conjunto característico de pacientes, cujas particularidades exigiam zelos e serviços de um profissional que a notasse como um todo. Ainda segundo Martins (2000), esses novos especialistas dedicados ao estudo do corpo e da sexualidade feminina observaram que a natureza não havia criado um "macho imperfeito", como fora representada a figura feminina até então, mas sim, um ser com uma natureza própria e, principalmente, com uma função sociocultural determinada: a maternidade.

Dessa forma, compreendendo que o discurso médico teve um papel preponderante na consolidação da maternidade como norma essencial à vida da mulher, e sabendo da supremacia política de tal discurso sobre a vida, acredito que analisar, por meio das teses médicas, como esses profissionais construíam verdades e receituários sobre os corpos inférteis é relevante para o campo historiográfico e para os estudos de gênero.

Rodhen (2003) assim como Vieira (2008) apontam questões relevantes sobre o trabalho com documentação médica, em especial, as teses, pois muitas vezes tais documentos se apresentaram como cópias de trabalhos anteriores. Outro ponto levantado é a autoria do material, tendo em vista que era relativamente comum nas faculdades de medicina, alguns alunos encomendarem seus trabalhos de conclusão de cursos para outros alunos. Todavia, cabe destacar que esse artigo analisa exclusivamente teses do início do século XX. Nesse período já era obrigatório que alunos apresentassem suas teses com pelo menos um capítulo de "prática" ou observações de casos em hospitais. Desta forma, as teses aqui analisadas possuem ampla revisão bibliográfica, porém, também apresentam relatos e análises de casos.

Outro ponto que merece ser apontado é a própria denominação "tese médica". Não se trata de trabalho de doutorado ou qualquer curso complementar. Chamava-se "tese médica" o trabalho de conclusão de curso, obrigatório de ser entregue e defendido para se obter o grau de bacharel em 
medicina. Portanto, a documentação analisada foi produzida por jovens, na fase final de sua graduação. Outro ponto interessante das teses é que eram publicadas, muitas vezes com os custos pagos pelos próprios alunos/autores. Com isso, é possível afirmar que, mesmo em um grau limitado, as teses circulavam entre diferentes faculdades de medicina e é isso que explica o fato de uma tese ter sido defendida em uma determinada Universidade, mas também ser possível encontrar exemplar dela em outra instituição.

Para essa pesquisa foram utilizadas teses produzidas e publicadas pelos formandos em Medicina da Faculdade de Medicina do Rio de janeiro (FMRJ). Ricas em juízo de valor sobre as mulheres, a gestação e a maternidade, as teses usadas neste texto estão vinculadas às cadeiras de "Higiene" e de "Ginecologia e Obstetrícia". Elas informam também partes de relatos de "clínica médica", ou seja, relatos de atendimentos realizados pelo autor da tese em enfermarias femininas. Esse fato possibilitou analisar a estrutura das teses em si e também articular os discursos e as práticas em se tratando da ausência de gestação ou de abortos.

A primeira tese sobre essa temática encontrada nos arquivos da Fiocruz datada do século XX foi a obra intitulada La Femme, do médico francês Galtier Boissière, publicada em 1905. ${ }^{3}$ Trata-se na verdade de um livro, que consiste em uma descrição detalhada do corpo feminino e de suas "funções maternais". Além de detalhar e ilustrar, por meio de desenhos, partes do corpo feminino, como mãos e pés, essa obra procurou materializar o corpo da mulher e destacar as modificações ocorridas por meio da gravidez. As gravuras coloridas enriquecem a obra e mostram o crescente interesse médico pelo corpo da mulher, em especial pelos órgãos reprodutores, conforme as figuras a seguir:

\footnotetext{
${ }^{3}$ Essa obra não é classificada como tese médica, e sim como um livro. O médico em questão procurou detalhar com informações e gravuras os estudos sobre o corpo feminino. Não se trata aqui de um aluno de Medicina que redige um trabalho para obtenção de nota e aprovação, mas sim da publicação de um médico já renomado. A inclusão desse livro se deu pelo fato de encontrarmos informações que seriam posteriormente usadas pelos alunos de Medicina acerca do corpo feminino. Outra explicação é que a obra compõe o corpo documental da Biblioteca de Obras Raras de Manguinhos - FIOCRUZ.
} 
Figura 1 - Corpo feminino

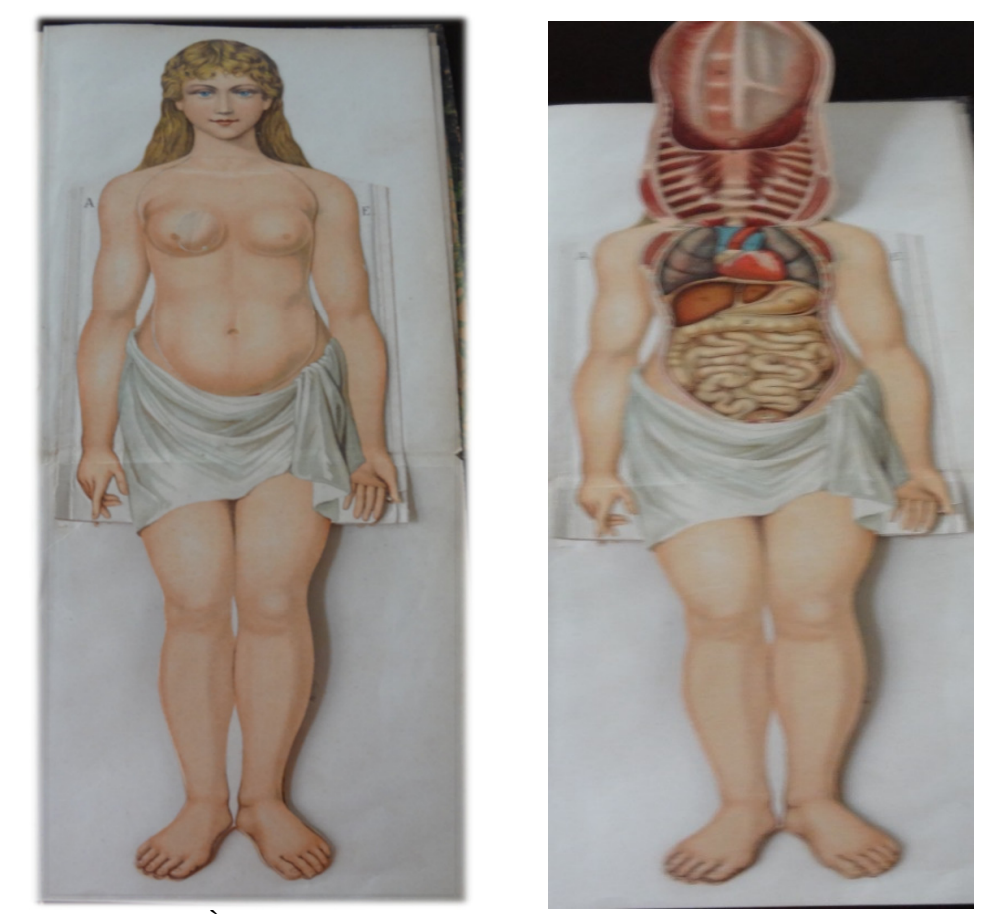

Fonte: BOISSIÈRE, Galtier. La Femme. Paris, 1905. Arquivo- Obras Raras Fiocruz

Fabíola Rohden (2003), ao debater sobre o conhecimento médico acerca do aborto, do infanticídio e da contracepção no início do século XX, demonstrou que os médicos se apresentavam como uma espécie de legisladores morais, que construíram ou reforçaram padrões e normas vinculados ao corpo feminino e, principalmente, ao comportamento sexual reprodutivo das mulheres. A fecundidade do corpo feminino era entendida como uma "bênção da natureza" e, em contrapartida, a esterilidade ou infertilidade foi paulatinamente sendo caracterizada como uma falha daquele corpo pelo discurso médico.

Para Vieira (2008), os médicos que se dedicavam aos estudos do corpo feminino, da fecundidade e da contracepção vão adquirindo um novo papel desde o início do século XX. Esses doutores se transformam em educadores e guardiões da moral, à medida que o projeto de medicalização social se amplia. Dessa forma, o exercício da maternidade passa a ocupar um lugar de destaque para o saber médico, e tal fato justifica a produção de livros e teses que versavam sobre o corpo feminino e sua função reprodutiva. 
Segundo o livro La Femme é possível verificar que o grande diferencial apresentado entre os corpos masculinos e femininos é a procriação. O detalhamento da reprodução é feito de forma a auxiliar os alunos, futuros médicos, a compreenderem as especificidades do corpo feminino e da gestação que nele ocorre.

A Figura 2 apresenta a exemplificação da valorização médica do corpo feminino grávido, conforme segue abaixo:

Figura 2 - Corpo feminino-gestante

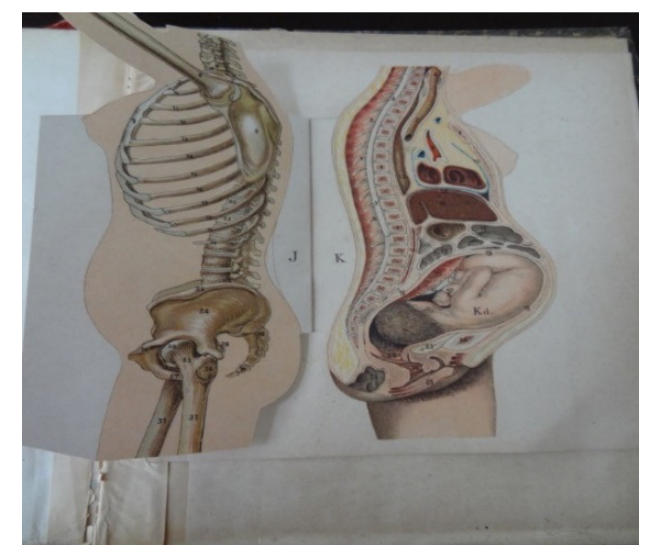

Fonte: BOISSIÈRE, Galtier. La Femme. Paris, 1905. Arquivo-Obras Raras- Fiocruz

O desejo de conhecer o corpo da mulher e compreender suas funções reprodutivas, suas doenças e mesmo suas potencialidades, se materializava na redação de teses desde meados do século XIX, encontradas em maior número no Brasil a partir do século XX. Todavia, os trabalhos que tratam das dificuldades para engravidar, da esterilidade ou mesmo do desejo de evitar filhos, são em número bem reduzido nas primeiras décadas do século XX.

Adentrando nos conteúdos propriamente ditos das teses, percebe-se que desde o início do século XX existia uma maior vinculação entre a chamada "revisão bibliográfica" sobre as temáticas escolhidas pelos autores, e o que poderia se chamar de registros de observações clínicas. Assim, as teses do início do século XX apresentavam observações e intervenções dos alunos nas enfermarias, atendendo diversas mulheres em casos de dificuldades para engravidar, perda involuntária do feto ou mesmo questões diretamente relacionadas à infertilidade. 
Nas teses das primeiras décadas do século $\mathrm{XX}$, a experiência de maternidade aparece como "essencialidade", e a reprodução como o "destino" para todas as mulheres. Nesse sentido, conforme apontou Costa (1979), o processo de gravidez e sua manutenção com todos os cuidados possíveis eram apenas o início do longo caminho que as mães deveriam percorrer. As responsabilidades que envolviam as mulheres iam além de "segurar" crianças nos ventres, pois se relacionavam com a educação de seus filhos, o que levou ao processo de politização da maternidade.

Para Costa (1979), a figura da mulher-mãe compôs parte de uma espécie de missão civilizadora dos Estados Nacionais, e isso também foi amplamente utilizado no Brasil. A produção de indivíduos e corpos saudáveis para o progresso da Nação era uma das funções destinadas aos médicos e estes viam na mulher e na maternidade uma "área de atuação", um "campo de embates", onde as tradições e crendices deveriam ser substituídas por saberes clínicos e racionais, com vistas à elevação social e moral do país.

Nesse sentido, a gestação, a maternidade e os cuidados infantis faziam parte de um projeto civilizador que articulou discursos e práticas para um suposto avanço da espécie humana. Com a consolidação dessa ideia a ausência da maternidade, seja por escolha, seja por impossibilidade física, passou a compor o espaço do patológico.

Elza Berquó (2003) organizou um trabalho sobre o panorama da saúde reprodutiva no Brasil. Nesse projeto, a médica Elisabeth Moloni Vieira, professora do Departamento de Medicina Social da USP, traçou um histórico das políticas públicas de contracepção no Brasil. Para Vieira (2003), a reprodução humana colocada como uma escolha só viria a acontecer mediante o desenvolvimento de ideias sobre contracepção. Tais ideias se ligam a um duplo movimento social que envolveu os médicos. Num primeiro momento, as inovações e mudanças de valores que ocorrem predominantemente até a década de 1960, e no segundo, após a segunda metade do século XX, a contracepção 
passou a ser objeto e assunto médico. ${ }^{4}$ Vieira argumenta que o século XX pode ser dividido, em termos de planejamento familiar, nesses dois grandes momentos, e percebe uma interferência maior do saber médico nesse segundo momento.

Todavia, acredito que as teses médicas produzidas na primeira metade do século XX, demonstram que, mesmo tendo argumentações de cunho mais social do que clínico, o saber médico já se ocupava da reprodução humana, muito antes do desenvolvimento e da comercialização da pílula. Essa reflexão se alinha com os debates que compreendem o saber e o conhecimento médico como fontes de produção de determinadas verdades sobre os corpos e os comportamentos. Sendo assim, a pílula representa sim um divisor de águas sobre a reprodução humana, mas os enunciados médicos sobre as mulheres e seus corpos proferidos anteriormente ao seu desenvolvimento e comercialização também desempenharam papel de destaque na construção das representações de mulher mãe e da mulher não-mãe. Foi esse conhecimento que consolidou a infertilidade como uma doença, pois, embora a atuação médica sobre a infertilidade/esterilidade tenha se dado com maior força apenas no final do século XX, a mesma periodização não se verifica para o estigma moral da mulher que não conseguia engravidar ou então daquelas que por opção evitavam a gravidez por prolongado tempo.

\section{As teses médicas sobre mulheres sem filhos}

Em 1911, o médico Pedro Monteiro Gondim defendeu a tese "Da esterilidade da mulher e seu tratamento", pela cadeira de ginecologia e obstetrícia da Faculdade de Medicina do Rio de Janeiro (FMRJ). A tese, dividida em quatro capítulos, procurou apresentar causas para esterilidade e possíveis tratamentos. É bastante significativo que na introdução da obra, o médico fez menção também a possibilidade de esterilidade masculina. Sem

\footnotetext{
${ }^{4}$ Vieira (2003) aponta que o primeiro hormonal oral foi produzido no final da década de 1950. O nome comercial do produto era Enovid.
} 
aprofundar as questões clínicas das dificuldades dos homens, Gondim apenas menciona que entre casais jovens existem casos em que a dificuldade em gerar filhos está relacionada ao marido e não à esposa. Contudo, a tese versa apenas sobre as questões relacionadas ao corpo feminino e as possíveis dificuldades em gestar.

O primeiro grande problema vinculado à infertilidade na concepção médica do período estava relacionado a menstruação anormal. As alterações no ciclo menstrual são detalhadas no primeiro capítulo da tese e ao final dele são apresentados possíveis tratamentos para as anomalias. Mulheres que possuíam pouco sangue menstrual (menstruação parca), segundo Gondim, teriam mais dificuldades para engravidar pois sofreriam de "útero infantil". Nesses casos, segundo o médico, a medicina poderia agir de diferentes formas tais como aplicação de corretes elétricas no útero ou mesmo injeções para estimular o ciclo menstrual.

Já no capítulo dois, o médico argumenta que obstáculos para relações sexuais entre o casal, não deveriam ser considerados como causas de infertilidade. Nesse ponto apresenta em destaque o vaginismo. Recorrendo a bibliografia do período e aos tratamentos disponíveis, Pedro Gondim, relata o caso de uma senhora casada, com 22 anos de idade, e que sofria de vaginismo, fato que dificultava a gestação.

Ao analisar esse caso, Gondim aponta:

Uma mulher de 22 annos sofrendo de vaginismo, após unmeras tentativas infructuosas de cópula pelo marido, um médico foi chamado, etherisou a paciente e permitiu assim ao marido consumar o acto sexual. Uma nova tentativa de cópula feita a noite seguinte foi impossível. Chamada dum médico; etherisações que se repetiram durante um auno, duas a três vezes por semana. Nesse tempo a mulher concebeu e durante todo o período da gravidez a cópula foi possível (GONDIM, 1911: 24).

Em nenhum momento do relato o médico questiona a prática de usar éter e desacordar a mulher para que o marido pudesse consumar relações sexuais. Fato que na atualidade poderia ser caracterizado como estupro, em 1911 foi apresentado como um tratamento legítimo que permitia a um "corpo 
rebelde" engravidar e cumprir uma espécie de destino traçado para as mulheres. Desacordada por conta do éter, essa mulher de 22 anos engravidou. Estava "curada" e o tratamento apresentado como êxito profissional.

Para além de questões clínicas relacionadas à infertilidade, os médicos estavam atentos também para questões morais. No início do século XX, o medo da queda drástica de população fez com que os médicos se preocupassem com a maternidade e o desejo feminino em ter um filho. Na seleção documental, foi encontrado duas teses que tratam do chamado malthusianismo, e, em ambas, os ditos "perigos" da ausência de crianças são analisados por médicos, não do ponto de vista clínico da infertilidade, mas do ponto de vista moral.

Em 1913, o médico recém-formado João de Miranda Costa apresentou tese à Cadeira de Higiene da Faculdade de Medicina do Rio de Janeiro, intitulada "A restricção da Natalidade". Por meio desse documento, pode-se observar a importância dada à instituição social da maternidade, pois a restrição à gravidez foi caracterizada como perigosa não apenas para o futuro da mulher, mas também para o futuro da Nação.

A primeira frase da tese apresentada por Miranda Costa reforça o ideal de maternidade: "Abramos lucta contra a restricção da natalidade! Depois da liberdade de pensar, diz Fiessinger ${ }^{5}$, só a liberdade de procriar!" (Costa, 1913, s/p). Nessa obra, é possível perceber claramente como a procriação e os cuidados maternos estavam articulados com um ideal de nacionalidade e desenvolvimento nacional.

Ao se referir sobre o controle de natalidade argumentou:

Tentemos, pois, luctar contra este mal deplorável que invade o socialismo moderno, corrompendo a moral, a família e a sociedade contemporânea! Uma sociedade que trabalha e que lucta em um mundo de progresso e civilização nunca poderá deixar-se vencer por um desejo implacável e absurdo de querer voluntariamente restringir a procriação. A estrutura moral e a coesão social a isso se opõem tenazmente (COSTA, 1913, s/p).

Por meio desse tipo de articulação discursiva, os médicos demonstravam estar em concordância com outros discursos, como o religioso e

\footnotetext{
${ }^{5}$ Médico francês que viveu no início do século XX.
} 
o jurídico. Percebe-se o surgimento e a consolidação de uma lógica educativa para os corpos, em especial os corpos femininos, que por diferentes motivos deveriam necessariamente vivenciar a gestação, o parto, o puerpério e se desdobrar em cuidados maternais. Assim, a "invenção" da necessidade feminina de maternidade ${ }^{6}$ foi construída como projeto da modernidade ocidental e amplamente difundida e consolidada pelo discurso médico desde o século XIX, mas principalmente a partir das primeiras décadas do século XX.

Ao se ler a tese de João Miranda Costa, nota-se como a recusa feminina à maternidade, não importando os motivos, causava um certo espanto e questionamento. Uma "mulher normal" deveria desejar ardentemente ser mãe e amar de forma plena e incondicional a vida do feto e depois a criança nascida. Misturando elementos discursivos da esfera religiosa e da esfera científica, esse médico argumentou que as mulheres não-mães estavam condenadas à infelicidade, bem como os seus maridos.

Jacob tinha por mulheres as duas irmãs Léa e Rachel. Quando Rachel viu que não tinha filhos, mandou Léa a Jacob e disse-lhe: "Dae-me filhos ou morrerei" (Gen. Cap. XXX). A Bíblia, que nos narra todos esses factos e ainda outros análogos, nos mostra claramente com que anseio naqueles tempos se invocava a fortuna de ter um filho! A dor da infertilidade sobrepujava todas as outras dores, inclusive a da morte, e, por isso mesmo, a procriação era o ideal de todos os povos, o sonho de todas as mães! (COSTA, 1913 : 9).

Dentro da lógica da maternidade compulsória articulada pelo discurso médico, as mulheres que não passaram por essa experiência foram representadas de um modo caricaturesco, e até mesmo estigmatizadas. Por ser o início do século XX um período de extrema valorização da criança, a maternidade foi vista como a verdadeira essência da mulher, ou seja, estava inscrita na própria "natureza feminina".

\footnotetext{
${ }^{6}$ Utilizo a ideia de invenção da necessidade dialogando com Badinter (1985; 2011), Aries (1981) e Forna (1999) que abordam a maternidade da forma como a conhecemos hoje, como uma invenção da modernidade.
} 
Para aquelas mulheres que não quisessem ou não pudessem ser mães, os médicos eram implacáveis nas acusações e na marginalização. Eram vistas como seres incapazes.

Ainda na mesma tese, observamos o seguinte trecho que materializa essa lógica da maternidade compulsória:

No mundo animal, o amor dos sexos e o instincto reproductor, são como uma lei universal de todos os seres, que se abraçam e se confundem no horizonte da vida! São os comportamentos que consolidam a base do lar e a vida superior da alma, estatuindo a segurança intima e harmoniosa da família. É a natureza viva, enfim, que brota adormecida no coração da mulher o sagrado instincto da procriação. Assim, a geração seria o fim principal do casamento e a união conjugal não seria somente a união de dous corpos, o acordo de duas inteligências, a fusão de dous corações! O filho seria o centro de todas as idéias, o ideal de todos os prazeres [...]. (COSTA, 1913: $11)$.

Seguindo a linha que procura estabelecer a maternidade como condição da "natureza feminina", o médico estabeleceu duras críticas para qualquer tipo de controle da reprodução humana, pois, para ele, existia um dever moral de procriação em todas as mulheres dado pela natureza. Percebese, portanto, que ao construir como verdade científica a educação dos corpos para a maternidade, o discurso médico do início do século XX condenou o sexo e o prazer sem a vinculação com a procriação. Segundo o médico:

Infelizmente, porém, o sentimento humano transgride com a moda dos tempos e os cônjuges longe de manter a sua preservança [sic] praticam a sua fraude, violando a procriação com a esterilidade voluntária. [...] Assim, a redução voluntária das gravidezes, determinando a diminuição da natalidade, produz forçosamente o enfraquecimento total das nações. O homem, sob o ponto de vista social, não tem o direito de restringir a natalidade, uma vez que não lhe é dado aniquilar uma função da natureza, que, por assim dizer, não é sua e pertence a sociedade inteira (Costa, 1913: 13).

As palavras do médico antecipam as considerações desenvolvidas por Fernando de Magalhães, o "pai" da obstetrícia no Brasil. No livro Obstetrícia Forense, lançado em 1933, Magalhães argumenta que o "aparelho sexual" da mulher na realidade não pertence a ela, mas sim à espécie humana. Nesse 
sentido, ela deveria apenas zelar para que seu corpo produzisse as boas crianças necessárias ao fortalecimento da família e da nação.

Todavia, um fato peculiar parece ter ocorrido na sociedade em relação a ter filhos, pois ao mesmo tempo em que se verificou a constante valorização da gestação, da maternidade e da criança, se processou um paulatino declínio na taxa de natalidade, principalmente na segunda metade do século XX em diversos países do mundo, incluindo o Brasil. A família brasileira se transformou. Segundo os dados do IBGE (Censos 1940 a 2000), a taxa de fecundidade vem diminuindo sistematicamente, pois nas décadas de 1940-1960 estava em torno de seis filhos por casal. Todavia, demógrafos e peritos em estudos de população começaram a notar o declínio da fecundidade na década de 1970, o que vem se acentuando até o início do século XXI. Em 1970, de acordo com os dados do IBGE, a taxa de fecundidade das brasileiras girava em torno de 4.2 filhos por casal. Ainda segundo o Instituto, a taxa caiu para 2,8 entre os anos de 1980 e 1990, e em 2000 o registro foi de 2,44 filhos por casal.

Além das mudanças quantitativas, também mudou a natureza das relações e, ao despontar do século XXI, a fórmula tradicional - pais e filhos morando sob o mesmo teto -, embora ainda seja majoritária, deixou de ser o único modelo familiar (THERBORN, 2006).

Debatida amplamente por diferentes segmentos da sociedade, a natalidade passou a ser encarada como política de Estado. A grande e soberana nação necessitava de indivíduos para ter continuidade. Segundo Therborn (2006), para grande parte dos países da Europa Ocidental, a fim de se manter uma boa quantidade de população, era necessário que as mulheres tivessem em média dois filhos por casal: um para substituir o pai e outro para substituir a mãe depois da morte de seus progenitores.

O contexto sociopolítico que auxiliou na redução da natalidade se vincula à compreensão da reprodução humana como uma escolha e não como um destino, como foi amplamente propagado pela medicina brasileira até os primeiros anos do século XX. Segundo Vieira (2003), a queda da fecundidade no Brasil não ocorreu como uma consequência de política nacional deliberada 
para tal fim, mas sim como um processo de política implícita de controle populacional. Enquanto países europeus estavam limitados territorialmente, o Brasil tinha vastos espaços desabitados. Dessa forma, o Estado Nacional não precisou incentivar diretamente a queda de natalidade. O processo, todavia, ocorreu, mas o caso brasileiro é ilustrativo, pois trata de uma política nacional que colocou no mercado contraceptivos orais com preços acessíveis e facilitou a esterilização feminina. ${ }^{7}$

As mulheres, de um modo geral, foram muito férteis até a metade do século XX. A cultura de valorização da família numerosa, assim como a inexistência de práticas anticoncepcionais eficientes, assegurava o grande número de filhos nas famílias do período. Porém, a década de 1960 apresentouse como um divisor de águas na política da fertilidade humana. A chamada "Revolução Sexual" que veio acompanhada do advento da pílula e, posteriormente, de outros métodos contra a gravidez aumentou o controle feminino sobre seu próprio corpo, diminuiu o número de crianças, e as mulheres passaram a ter maior controle sobre sua sexualidade, chegando, em alguns casos, a optar por nunca ter filhos.

Para se entender esse fenômeno da "transição demográfica" a respeito da natalidade, é preciso investigar o fato de que, muito antes da "invenção da pílula" ou da chamada "revolução sexual", os médicos já estavam preocupados com a opção pela não maternidade ou mesmo pela redução no número de filhos.

Esse é o caso da tese apresentada por Luiz Gonzaga Vianna Barbosa à Faculdade de Medicina do Rio de Janeiro, em 1911. O título escolhido pelo médico foi Malthus no Brasil - prophylaxia da depopulação. Desde o início de seu texto, Luiz Gonzaga argumenta sobre a necessidade de incentivar o crescimento populacional no Brasil para preencher o chamado "vazio

\footnotetext{
7 Segundo Elza Berquó, André J. Caetano defendeu tese de doutorado na University of Texas, no ano 2000, demonstrando que existia compra de votos na região nordeste do país em troca de realização de cirurgias de esterilização: CAETANO, Andre J. Sterilization for votos in the Brazilian Northeast. The case of Pernambuco. Tese. (doutorado), Universityof Texas. Austin, 2000. Elza Berquó publicou resultados de pesquisa na revista Estudos Feministas, onde aponta para a existência de inquéritos com o objetivo de esclarecer as origens das esterilizações em massa no Brasil: BERQUÓ, E. Brasil. Um caso exemplar: anticoncepção e partos cirúrgicos à espera de uma ação exemplar. Estudos Feministas, v. 1, n. 2, p. 366-381, 1993.
} 
demográfico", pois, segundo ele, o território comportaria cerca de 500 milhões de habitantes, e no início do século as estatísticas aproximadas davam conta de informar que o território dispunha de cerca de apenas 20 milhões de habitantes. Esse número foi motivo de preocupação para o médico não apenas por questões relacionadas à saúde pública ou por dificuldades clínicas em engravidar, mas principalmente por questões de ordem moral e patriótica, como pode-se observar na transcrição do trecho abaixo:

Mas há necessidade de usarmos aqui toda a franqueza: este crescimento [populacional] - muito vagaroso e muito indolente, não satisfaz em absoluto. D`ahi o perigo de d`uma hora para outra, o nosso grande paíz- que de tantos braços necessita- descambar para a cachexia desoladora da depopulação! E não foi sem argumentos legítimos que levantamos esta hypóthese. Estados existem no Brasil, cujo número de habitantes diminui a cada anno. (BARBOSA, 1911: s/p).

Ao longo das argumentações de sua tese, Luiz Gonzaga Barbosa fala da importância das "correntes migratórias", ou seja, dos imigrantes que desde meados do século XIX se aventuraram em terras brasileiras. Para o médico, a crescente onda de imigração branca europeia para o país só traria ganhos em termos populacionais e progresso, todavia, ainda não seria suficiente para povoar adequadamente a nação.

No capítulo quatro de sua tese, o médico inicia uma espécie de receituário para evitar a diminuição da população. Após debater e contestar longamente a teoria malthusiana e sua aplicação no Brasil nos primeiros três capítulos, Luiz Gonzaga Barbosa inicia esse seu quarto capítulo justamente tentando demonstrar as formas de se aumentar a população, com vista ao fortalecimento nacional. A primeira grande regra enunciada pelo médico é com relação às crianças, mais especificamente com relação à mortalidade infantil, mencionando as causas naturais, acidentais e criminosas que eram amplamente praticadas no país para eliminar crianças.

Dialogando com o médico argentino Emilio Coni, que pesquisou a mortalidade infantil em Buenos Aires no início do século XX, Barbosa afirmou que a primeira profilaxia para evitar a morte de crianças seria a "legitimidade". 
Nesse sentido é que argumenta que, para além de questões clínicas, a infertilidade e a ausência de maternidade por opção definitiva ou temporária vão além do aspecto médico e penetram aspectos morais. Assim, o médico segue com as sugestões de como evitar os perigos do malthusianismo no Brasil pela valorização da infância e da maternidade. Para ele, era urgente:

$1^{\circ}$ Combater a ilegitimidade, favorecendo o casamento, e suprimindo da legislação actual os obstáculos que o impedem;

$2^{\circ}$ Estabelecer pequenos asylos de maternidade, com fim de cuidar das mulheres pobres, que mostrem repugnância pelo Hospital; ou ainda para assistir em domicilio solicitando para isso o concurso das casas de caridade;

$3^{\circ}$ Estimular o aleitamento materno vulgarizando as regras de aleitamento mixto e do aleitamento artificial;

$4^{\circ}$ Estabelecer uma sabia e prudente vigilância sobre o aleitamento mercenário;

$5^{\circ}$ Crear sociedades protectoras da infância, cujos fins seriam análogos aos que existem em outros paizes [...];

$6^{\circ}$ Estas sociedades devem auxiliar as mães pobres no aleitamento de seus filhos, distribuindo com profusão pequenos opusculos sobre a hygiene domestica, nos quaes estariam explicados de um modo claro e ao alcance das massas as regras de hygiene da alimentação, asseio, vacinação, etc. do recém-nascido;

$7^{\circ}$ Fundar estabelecimentos com o nome de creches para receber durante o dia as crianças de um a dois annos, enquanto que as mães pobres executam o seu trabalho cotidiano;

$8^{\circ}$ Animar por meio de leis protectoras a construcção de cidades operárias reunindo as condições de hygiene necessárias;

$9^{\circ}$ Adoptar disposições enérgicas para obter isolamento das moléstias infecciosas;

$10^{\circ}$ Decretar vaccinação e revacinação obrigatórias;

$11^{\circ}$ Combater a propagação das moléstias venéreas e syphiliticas, perseguindo a prostituição clandestina (BARBOSA, $1911: 105$ ).

O médico ainda segue mencionando a necessidade de palestras e outros trabalhos informativos para a proteção da infância, assim como o incentivo à gestação e à "maternidade consciente", que seria a mãe educada e educadora.

Scavone (2001) aponta que existiu no Brasil, assim como na maioria dos países que pretenderam entrar numa simbólica “modernidade”, uma 
extrema maternalização das mulheres. Esse processo, datado do século XVIII, foi amplamente analisado por Badinter $(1985 ; 2011)$ e foi sendo estendido para diversos âmbitos da vida social. A maternidade cuidadosa, higiênica, pedagógica, foi se alastrando como um projeto de modernidade e, como verificado aqui, foi amplamente divulgada pelo discurso médico. Nesse sentido, os debates médico-morais sobre os cuidados com a infância, o combate às doenças e os cuidados puerperais ajudam a compor um cenário de valorização da mãe em detrimento às mulheres que, por diferentes motivos, não são mães.

Ainda segundo Scavone (2001), o processo de maternalização das mulheres se desenvolveu em dois eixos centrais: o primeiro relacionado mais especificamente com a medicalização da maternidade na tentativa de controlar os abortos, infanticídios e mesmo a mortalidade infantil; e o segundo se caracterizou pela eficaz tentativa de transformar as mães, seus hábitos e até seus sentimentos em algo sempre positivo em relação à criança em seu ventre e, posteriormente, em sua vida. Esse segundo eixo se relacionou com o processo de instrução das mães, uma espécie de pedagogia da maternidade com vistas à depreciação em alguma medida das mulheres não-mães.

Neste sentido, a análise da tese apresentada por Severino Vieira Cesar, no ano de 1924, onde o corpo feminino infértil foi campo de investigação e questionamento, é profícua. Com o título Contribuição ao estudo da infertilidade na mulher, a tese, aprovada com distinção na cadeira de ginecologia, teve como eixo central listar, classificar e analisar os diferentes motivos que tornavam uma mulher infértil, privando-a, portanto, da maternidade.

Para o médico, a justificativa para a escolha do tema se deu pelo fato de ser uma temática muito debatida entre os médicos nos anos de 1920 e, também, pelo fato de ser "[...] este thema a pedra angular que preside o futuro de nossa raça, o índice da natalidade, o progresso de nossa população e o engrandecimento de nossa pátria." (CESAR, 1924, s/p). Novamente aqui se percebe o discurso médico articulado com as ideias de declínio demográfico e a necessidade de estímulo à maternidade. 
É ainda significativo nessa tese o fato de as questões biológicas que "atrapalham" a maternidade não serem as únicas analisadas pelo médico. Além de capítulos técnicos sobre as disfunções e complicações hormonais, Severino Cesar aponta que existe outro tipo de infertilidade muito mais difícil de tratar, que seria aquela provocada pelo desejo feminino de evitar crianças.

Ao apresentar as formas como os médicos deveriam auxiliar na realização da maternidade, seja ela de escolha ou "compulsória", o médico argumenta:

Como podemos evital-á? [a esterilidade]
Primeiramente dando ensinamentos precisos a estas criaturas
que todo o dia nos chegam ao ambulatório hospitalar,
manifestando o desejo ardente de se tornarem mães,
sujeitando-se, a todos os meios que lhes foram indicados
combater o seu mal.
Devemos instruir precisamente as jovens que desejam
contrair o matrimonio fecundo, com mais razão as que são
inexperientes no assumpto, lhes mostrando as grandes
inconveniências, ou melhor, os grandes perigos que podem
sobrevir após ter contraído uma moléstia infecciosa (...)
As mães de família teem, mais do que qualquer outra pessoa,
a obrigação moral, de mostrarem às suas filhas, as
transformações pelas quaes ellas passam, após, uma certa
idade, pois isto póde fazer pelas suas experiências próprias.
(CESAR 1924: s/p).

Por esse trecho, se percebe que o eixo central da argumentação não é clínico, e sim moral. Assim, as doenças, a vida sem regras, ou mesmo a "ignorância" de algumas mulheres, deveriam ser combatidas pelo conhecimento médico e com a ajuda das mães devidamente instruídas por esse mesmo conhecimento.

Como afirma Schwengber (2006), ao redor dos corpos classificados como femininos, vai se consolidando paulatinamente um conjunto de práticas e saberes, além de políticas públicas e de aperfeiçoamento com vistas à maternidade e à maternagem. Tais debates compõem parte do que podemos classificar como um discurso médico sanitarista que visava convencer as mulheres de sua vocação natural para a maternidade, pois a própria fisiologia de seu corpo apontava para isso. 
Todavia, nem todos os corpos estavam em condições de gestar e parir, assim como nem todas as mulheres desejavam ser mães. Tais indivíduos deveriam ser investigados, classificados e, por fim, curados, com vistas ao engrandecimento da espécie, da nação e da própria mulher. Essa era a forma como o conhecimento médico tratava a ausência de crianças nos corpos femininos.

Porém, quando tratava das mulheres que por diversas razões evitam as crianças e até chegam ao ponto de tentar a esterilidade, o médico as classificou como desafio lançado à natureza, pois estavam na contramão de tudo o que se acreditava como sendo "naturalmente" feminino. Para ele,

Os casos desta natureza são inumeráveis e o médico se acha completamente desarmado para combatel-a.

Infelizmente estas pacientes privam-se systematicamente das alegrias dos actos physicologicos da fecundação, indo de encontro das leis santas da natureza.

Pelo seu orgulho fútil e irrasoavel, meramente pela ideia vã e efhemera de ser sempre jovem e bella, a mulher se esquece do velho adagio sérvio, respeitado entre os Eslavos, que dizia: "A mulher não é mulher enquanto não tem filhos". (CESAR, 1924: 15).

Severino Cesar segue em sua lógica de disciplinamento dos corpos, colocando em franca oposição esse grupo de mulheres classificadas por ele como fúteis, e as outras mulheres, consideradas sofredoras, pois desejavam a maternidade, sem, contudo, conseguir a "felicidade naturalmente" provocada pela gestação. Nesses casos, caberia sim uma intervenção médica para "ajudálas" a realizar o sonho da maternidade. Essas mulheres inférteis, mas desejosas de filhos, eram descritas como vítimas, que precisavam ser amparadas pelos médicos. Para Severino Vieira Cesar:

Felizmente, uma cousa nos consola: enquanto umas com seu orgulho, outras, com sua ideia magnanime e altruística, teem o desejo ardente de ser mãe, sem ás vezes conseguir. Este desejo é tão grande ás vezes, que acontece tornar-se uma ideia fixa, concentrando todos os pensamentos levando-a quase a loucura, obrigando o médico a intervir, ás vezes, com grande sucesso. (CESAR, 1924:15).

As mulheres são, portanto, classificadas nesses dois grandes grupos: as que optam ou evitam a maternidade, e aquelas que sofrem por não conseguirem 
engravidar. Ambos os grupos foram vistos como patológicos, pois caberia ao médico tentar curar as inférteis desejosas de crianças e combater a queda da natalidade por meio de uma ampla educação moral. Despertando na mulher o desejo de filho e a fazendo contribuir para os avanços da nação ao gerar filhos saudáveis e educá-los com dedicação. Para o médico, a escolha pela infertilidade é um dos atos "mais graves, dos mais ofensivos, e dos mais hediondos que a mulher pode apresentar na sociedade!... Ai de nós, se assim não fosse!..." (CESAR, 1924: 16).

Mulheres inférteis e mulheres que evitavam a gestação por prolongado período eram desafios lançados aos médicos. O temor da queda populacional ou o desarranjo familiar que a ausência de filhos poderia causar preocupavam alguns jovens médicos. Tema recente no campo historiográfico, a história da infertilidade é um dos campos para se analisar as representações e discursos sobre mulheres.

\section{Considerações Finais}

Ao tratar da história da sexualidade, Foucault (1999) percebe a reprodução como uma das questões principais dos processos econômicos e políticos. Dessa forma, a sexualidade reprodutiva se caracterizou como um importante meio de controle das populações. Nesse sentido, a preocupação com a saúde da população, em especial a saúde reprodutiva ganhou espaço nas áreas do conhecimento médico e nas políticas de Estado.

Para Schwengber (2006 : 25),

[...] não eram apenas os corpos daqueles que trabalhavam que interessavam ao Estado Brasileiro, mas especificamente os corpos que iriam ser gerados. Reconheciam-se esses corpos como estratégicos, uma vez que poderiam melhorar e até aperfeiçoar a espécie.

Dessa forma, a medicina, ancorada no ideal de cientificidade, se coloca como a grande ordenadora social dos corpos, dos prazeres e da reprodução. Os médicos acreditavam que seu papel também incluía a orientação de mulheres, 
livrando-as de sua "ignorância" sobre a maternidade, e, sendo assim, tornaramse os grandes agentes da politização da maternidade no início do século XX.

As Faculdades de Medicina e, em especial, a Faculdade de Medicina do Rio de Janeiro, foram centros de produção de conhecimento sobre os corpos femininos. Porém, muito além de saberes médicos e tratamentos clínicos, tal espaço de conhecimento foi também centro de uma produção de ideal de gestação, de corpo e de maternidade. Uma maternidade higiênica, normatizada, e que determinaria uma espécie de função social feminina: a geração de crianças.

A batalha contra doenças, como por exemplo, a sífilis, esteve no centro dos debates médicos no início do século XX também com o intuito de evitar abortos ou mesmo infertilidades (VÁZQUEZ, 2018 a). O corpo feminino almejado pelos médicos era um corpo perfeito para a procriação e controlado sexualmente. Liberdades sexuais, potenciais geradoras de doenças e abortos, foram duramente reprimidas. A gestação saudável era o bem a ser alcançado por todas nesses discursos.

As teses, fontes primeiras do saber que circulava nas faculdades de medicina, mantiveram uma certa hegemonia sobre esse conhecimento até a primeira metade do século XX. Como aponta VÁZQUEZ (2018 b), a partir de meados do século, esse saber foi paulatinamente se popularizando, e não permaneceu restrito especificamente nos círculos fechados das Faculdades de Medicina e dos textos científicos, passando a ser divulgado por diferentes meios, dentre eles mídias impressas de maior circulação. A infertilidade feminina passou a ser debatida em círculos ampliados.

Novos tratamentos e conhecimento surgiram para potencializar a gestação, contudo, o mais significativo é o fato de que mulheres inférteis finalmente deixaram de ser tratadas como "anormais". Gerar e parir, embora experiências desejadas por boa parte das mulheres na atualidade, não são classificadas como essenciais dentro do conhecimento médico. Maternidade, enfim, não é destino. 
Referências

ARIÉS, P. História Social da Criança e da Família. Rio de Janeiro: LTC, 1981.

BADINTER, E. Um amor conquistado: o Mito do Amor Materno. Rio de Janeiro: Nova Fronteira, 1985.

BADINTER, E. O Conflito: a mulher e a mãe. Rio de Janeiro: Record, 2011.

BARBOSA, L. G. V. Malthus no Brasil.1911. 144f. Tese. (Cadeira de Hygiene)- Faculdade de Medicina, Faculdade de Medicina do Rio de Janeiro, Rio de Janeiro, 1911.

BERQUÓ, E. (org) Sexo e vida: panorama da saúde reprodutiva no Brasil. Campinas: Unicamp, 2003.

BERQUÓ, E. Brasil: um caso exemplar. Anticoncepção e partos cirúrgicos à espera de uma ação exemplar. Estudos Feministas, Florianópolis, v. 1, n. 2, p 366-381, 1993.

BOISSIÈRE, G. La Femme. Paris: Schleicher Frères \& C. Éditeurs, 1905.

CESAR, S. V. Contribuições ao estudo da esterilidade da mulher. 1924. 251f. Tese. (Cadeira de Clínica Gynecológica)-Faculdade de Medicina, Faculdade de Medicina do Rio de Janeiro, Rio de Janeiro, 1924.

CORRÊA, S.; ÁVILA, M.B. Direitos sexuais e reprodutivos: pauta global e percursos. IN: BERQUÓ, E. (org) Sexo e vida: panorama da saúde reprodutiva no Brasil. Campinas: Unicamp, 2003.

COSTA, J. de M. A restricção da natalidade.1913. 188f. Tese. (Cadeira de Hygiene)- Faculdade de Medicina, Faculdade de Medicina do Rio de Janeiro, Rio de Janeiro, 1913.

COSTA, J. F. Ordem médica e a norma familiar. 4ed. Rio de Janeiro: Graal, 1979.

FORNA, A. Mãe de todos os mitos: como a sociedade modela e reprime as mães. Rio de Janeiro: Ediouro, 1999.

FOUCAULT, M. A política da saúde no século XVIII. In: FOUCAULT, M. Microfísica do poder. Rio de Janeiro: Graal, 2000.

FOUCAULT, M. História da sexualidade I. A vontade de saber. Rio de Janeiro: Graal, 1999. 
GONDIM JUNIOR, P. M. Da esterilidade da mulher e seu tratamento.1911. 76f. Tese.( Cadeira de Clínica Obstetrica e Gynecologica)- Faculdade de Medicina, Faculdade de Medicina do Rio de Janeiro, Rio de Janeiro, 1911.

MARTINS, A.P.V. Dar a Luz. Experiências da maternidade na transição do parto doméstico para o hospitalar. Relatório de pós-doutorado. Rio de Janeiro, FIOCRUZ, 2004.

MARTINS, A.P.V A medicina da mulher: visões do corpo feminino na constituição da obstetrícia e da ginecologia do século XIX 2000. 311f. Tese (Doutorado em História) - Faculdade de Filosofia de Ciências Humanas, UNICAMP, Campinas, 2000.

MATOS, M. I. Em nome do engrandecimento da nação: representações de gênero no discurso médico- São Paulo 1890-1930. Diálogos, Maringá, v 4, n. 4, p. 77-92, 2000.

MOULIN, A. M. O corpo diante da medicina. In: COURTINE, J; CORBIN,A. História do Corpo. Petrópolis: Vozes, 2008.

RAGO, M. Dizer sim a existência. In RAGO, M. (org) Para uma vida não fascista. Autentica, 2009.

ROHDEN, F. A arte de enganar a natureza. Contracepção, aborto e infanticídio no início do século XX. Rio de Janeiro: Fiocruz, 2003.

ROHDEN, F. Uma ciência da diferença: sexo e gênero na medicina da mulher. Rio de Janeiro: Fiocruz, 2001.

SCAVONE, L. A maternidade e o feminismo: diálogos com as Ciência Sociais. Cadernos Pagu, São Paulo, s/v, n 16, p.137-150, 2001.

SCHWENGBER, M.S.V. Distinções e articulações entre corpos femininos e corpos grávidos na Pais e Filhos. História: questões e debates, Curitiba, v 47, n 2, p. 123-138, 2007.

SCHWENGBER, M.S.V. Donas de Si? Educação de corpos grávidos no contexto a Pais e Filhos. 2006. 198f. Tese. (Doutorado em Educação)Faculdade de Educação, Universidade Federal do Rio Grande do Sul, Porto Alegre, 2006.

THERBORN, G. (org). Sexo e poder: a família no mundo 1900-2000. São Paulo: Contexto, 2006.

VÁZQUEZ. G.G.H. Vênus nos braços de mercúrio, bismuto e arsênio. Notas históricas sobre sífilis gestacional antes da penicilina. Sexualidad.Salud y Sociedad. Rio de Janeiro, v. 2, n. 28, p 226-245, 2018 a. 
VÁZQUEZ. G.G.H. Imperfeições no papel. A infertilidade nas páginas da Revista Pais \& Filhos. Revista Estudos Feministas, Florianópolis, v. 26, n 1, p. $1-14,2018$ b.

VIEIRA, E. A medicalização do corpo feminino. Rio de Janeiro: Fiocruz, 2008. VIEIRA, E. Políticas Públicas e contracepção no Brasil. IN: BERQUÓ,E. (org) Sexo e vida: panorama da saúde reprodutiva no Brasil. Campinas: Unicamp, 2003.

VILLELA, W.; ARILHA, M. Sexualidade, gênero e direitos sexuais e reprodutivos. In: BERQUÓ, E. (org) Sexo e vida: panorama da saúde reprodutiva no Brasil. Campinas: Unicamp, 2003.

Recebido em: 13 de novembro de 2019 Aceito em: 28 de fevereiro de 2020 